Claremont Colleges

Scholarship@ Claremont

Pomona Faculty Publications and Research

Pomona Faculty Scholarship

5-4-2010

\title{
Kinematic Evidence for Superfast Locomotory Muscle in Two Species of Teneriffiid Mites
}

Grace C. Wu

Pomona College

Jonathan C. Wright

Pomona College

Dwight L. Whitaker

Pomona College

Anna N. Ahn

Harvey Mudd College

\section{Recommended Citation}

"Kinematic evidence for superfast locomotory muscle in two species of teneriffiid mites," Grace C. Wu, Jonathan C. Wright, Dwight L. Whitaker and A. N. Ahn, J. Exp. Bio. 213, 2551-2556, (2010). doi: 10.1242/jeb.024463.

This Article is brought to you for free and open access by the Pomona Faculty Scholarship at Scholarship @ Claremont. It has been accepted for inclusion in Pomona Faculty Publications and Research by an authorized administrator of Scholarship @ Claremont. For more information, please contact scholarship@cuc.claremont.edu. 
The Journal of Experimental Biology 213, 2551-2556 (C) 2010. Published by The Company of Biologists Ltd doi:10.1242/jeb.024463

\title{
Kinematic evidence for superfast locomotory muscle in two species of teneriffiid mites
}

\author{
Grace C. Wu ${ }^{1}$, Jonathan C. Wright ${ }^{1, \star}$, Dwight L. Whitaker ${ }^{2}$ and A. N. Ahn ${ }^{3}$ \\ ${ }^{1}$ Department of Biology, Pomona College, Claremont, CA 91711, USA, ${ }^{2}$ Department of Physics, Pomona College, Claremont, CA \\ 91711, USA and ${ }^{3}$ Department of Biology, Harvey Mudd College, Claremont, CA 91711, USA \\ *Author for correspondence (jcw04747@ pomona.edu)
}

Accepted 4 May 2010

\begin{abstract}
SUMMARY
Locomotory muscles typically operate over a narrow range of contraction frequencies, characterized by the predominant fiber types and functional roles. The highest documented frequencies in the synchronous sound-producing muscles of insects (550 $\mathrm{Hz})$ and toadfish $(200 \mathrm{~Hz})$ far exceed the contraction frequencies observed in weight-bearing locomotory muscles, which have maximum documented frequencies below $15-30 \mathrm{~Hz}$. Laws of scaling, however, predict that smaller arthropods may employ stride frequencies exceeding this range. In this study we measured running speed and stride frequency in two undescribed species of teneriffiid mites from the coastal sage scrub of southern California. Relative speeds of both species [129-133body lengths $(B L) \mathrm{s}^{-1}$ ] are among the fastest documented for any animal. Measured stride frequencies for both species far exceed those documented for any weight-bearing locomotory muscle, with measured values for one species ranging from $93 \mathrm{~Hz}$ at $25^{\circ} \mathrm{C}$ to $111 \mathrm{~Hz}$ at $45^{\circ} \mathrm{C}$. Stride frequencies either closely approximate or, for one species, exceed predicted values based on an interspecific scaling of frequency and animal mass. Consequently, while the ultra-high frequencies of these muscles must depend on appropriately scaled kinetics of the calcium transient and contraction-relaxation cycle, these do not appear to limit the operating frequencies during running. The predicted low muscle forces operating at these very high frequencies evidently suffice for locomotion, probably because of the larger relative muscle force generated by smaller animals.
\end{abstract}

Key words: teneriffiid mite, stride frequency, superfast muscle.

\section{INTRODUCTION}

Rapid locomotion in animals requires rapid and cyclical muscle performance. With the exception of the asynchronous flight muscles of some insects, which have a lower than 1:1 correspondence between neural impulse and muscular contraction (Pringle, 1949; Sotavalta, 1947; Sotavalta, 1952; Syme and Josephson, 2002), the fastest documented muscle contraction frequencies are seen in the sound-producing muscles of the toadfish swim bladder (Appelt et al., 1991; Rome et al., 1996), the flight muscles of whiteflies (Homoptera) (Byrne et al., 1998), and the tymbal muscles of cicadas (Josephson and Young, 1985). The toadfish Opsanus tau swim bladder muscles exploit the resonance properties of the bladder wall to achieve contraction frequencies up to $200 \mathrm{~Hz}$ at $25^{\circ} \mathrm{C}$, and the synchronous tymbal muscles of the cicada Okagana vanduzeei operate at $550 \mathrm{~Hz}$ at $40-45^{\circ} \mathrm{C}$. Reported contraction frequencies for weight-bearing locomotory muscles of terrestrial animals are significantly lower. Lizard and mouse fast-twitch fibers attain frequencies of $25-30 \mathrm{~Hz}$ at $35^{\circ} \mathrm{C}$ (Rome and Lindstedt, 1998), and cockroach leg muscles cycle at a comparable range during running $\left(15-27 \mathrm{~Hz}\right.$ at $\left.23-26^{\circ} \mathrm{C}\right)$ (Full and Tu, 1991).

The primary constraint on the operating frequencies of locomotory muscles is assumed to be the force-velocity trade-off (Rome and Lindstedt, 1998; Rome, 2006). High contraction frequencies necessitate appropriately scaled kinetics in all elements of excitation-contraction coupling and muscle relaxation. Some of these needs are met by specialized isoforms, including myosins, troponin $\mathrm{C}$ and the calcium ATPases. However, high-frequency contractions also impose quantitative trade-offs (Syme and Josephson, 2002). In particular, the rapid calcium removal necessary for fast relaxation depends on a high density of sequestering calcium ATPases and hence a large relative volume of the sarcoplasmic reticulum (SR). Furthermore, rapid cycling of myofibril cross-bridges competes with the SR for ATP and means that fast muscles must either be anaerobic or have a large mitochondrial volume. In both cases, the imposed reduction in myofibril volume lowers the maximum muscle force (Rome and Lindstedt, 1998). The consequences of these trade-offs are well demonstrated in the high-frequency aerobic tail shaker muscles of rattlesnakes and the aerobic tymbal muscles of cicadas in which myofibrils are reduced to relative volumes of $31 \%$ and $22 \%$, respectively (Schaeffer et al., 1996; Josephson and Young, 1985).

Because of their need to generate summed forces exceeding the animal's weight, weight-bearing muscles should be particularly constrained by the force-velocity trade-off. Laws of scaling predict that the significance of this trade-off should be particularly apparent at size extremes. It is well established that stride frequency decreases with increasing body size (Heglund et al., 1974; Pennycuick, 1975; Full, 1989; Biewener, 2003). This can be attributed to the relationship between stride frequency and limb length imposed by limb resonance. For running vertebrates, stride frequency $(f)$ scales with body mass $\left(M_{\mathrm{b}}\right)$ according to the following relationship (Pennycuick, 1975; Schmidt-Nielsen, 1984; Biewener, 2003):

$$
f \propto M_{\mathrm{b}}{ }^{-0.17} .
$$

Arthropods show a broadly similar trend of decreasing stride frequency with size (Full, 1989). Furthermore, animals with morphological locomotory designs differing in number of legs (bipedal, quadrupedal, hexapedal, octopedal), body geometry and 
skeletal design exhibit similar mass scaling effects, suggesting that terrestrial locomotion is subject to certain common constraints (Full, 1989; Full and Tu, 1991). These include, but are not necessarily limited to, energetic costs, precision of neuromuscular control and dynamic constraints (Jones and Lindstedt, 1993). Relative speed (speed per body length, $v_{\mathrm{r}} ; \mathrm{m} \mathrm{s}^{-1} B L^{-1}$ ) is also predicted to scale in proportion to $M_{\mathrm{b}}{ }^{-0.17}$, given that absolute running speed scales as $M_{\mathrm{b}}{ }^{0.17}$ (Schmidt-Nielsen, 1984). This is broadly supported by experimental data for mammals (Iriarte-Diaz, 2002), although the pattern is non-linear, with the negative relationship becoming more pronounced as mass increases.

The laws of scaling in locomotion have never been figured into the construct, modifications and constraints of superfast muscles, perhaps primarily because superfast synchronous locomotory muscles have not been well documented in comparison with superfast sonic muscles or the asynchronous flight muscles of insects. While we can reasonably predict that very small animals should show high stride frequencies and relative speeds based on allometry, it is unclear whether the predicted -0.17 exponent applies to animals below a mass of $10 \mathrm{mg}$. The force-velocity tradeoff might impose ultimate limits to stride frequency. However, as muscle force is proportional to myofibril cross-sectional area, and thus scales as $M_{\mathrm{b}}{ }^{0.67}$, the relative force $\left(\mathrm{N} \mathrm{kg}^{-1}\right)$ required to support an animal also decreases with body mass, scaling as $M_{\mathrm{b}}{ }^{-0.33}$ $\left(M_{\mathrm{b}}{ }^{0.67} / M_{\mathrm{b}}{ }^{1}\right)$. This raises the fundamental question of whether stride frequency in small animals is ultimately limited by the force-velocity trade-off at all. If not, the limits may be set by the kinetics of one or more components of the contraction-relaxation cycle.

As the smallest running animals, small arthropods are predicted to exhibit the highest stride frequencies. Good candidates for exceptional locomotory muscle frequencies include several species of fast-moving predatory mites. These animals provide excellent models for examining whether force-velocity constraints apply to animals approaching the extreme end of body size and locomotory performance trade-offs. To gain insight into the scaling effects of stride frequency and relative velocity, we investigated the kinematics of two species of teneriffiid mites collected from the coastal sage scrub of California. Based on the scaling relationships observed in running animals, we hypothesized that stride frequencies of both species would exceed values currently documented for terrestrial arthropods. We consider the implications of this study for the proposed constraints of superfast muscles.

\section{MATERIALS AND METHODS}

The Teneriffiidae is a cosmopolitan but poorly described family of prostigmatid mites. This family is characterized by the unique morphology of the palpal oncophysis, although there is disagreement over morphological descriptions of the main genera (McDaniel et al., 1976; Luxton, 1993; Judson, 1994). Species of Teneriffiidae have been described from a number of sage and saltbrush habitats in Oregon, South Dakota and Arizona (McDaniel et al., 1976; Krantz, 1978). The two species studied here are tentatively classified in the genus Parateneriffia (McDaniel et al., 1976) but neither is presently described.

Adult Parateneriffia spp. (Fig. 1A,B) were collected by aspirator from coastal sage scrub habitat at the Robert J. Bernard Field Station of the Claremont Colleges, Claremont, CA, USA. Species $1(B L$, 0.9-1.5 mm) was collected from small patches of debris on open alluvial gravel terrain from June to August in 2007 to 2009, and was active at ground temperatures exceeding $50^{\circ} \mathrm{C}$. Species $2(B L$, $0.5-0.7 \mathrm{~mm}$ ) was collected from oak litter in the autumn of 2007 and in the spring of 2008. Body lengths were measured from the
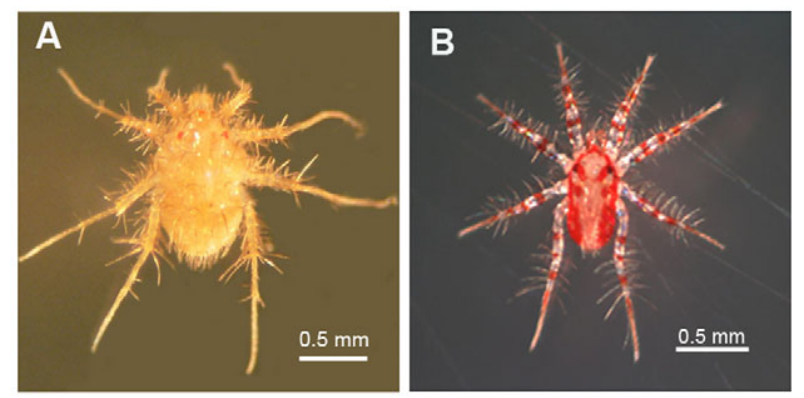

Fig. 1. Teneriffiid mites: species 1 (A) and species 2 (B). Species 1 ranges in body length from ca. $0.9 \mathrm{~mm}$ to $1.5 \mathrm{~mm}$, species 2 from $0.5 \mathrm{~mm}$ to $0.7 \mathrm{~mm}$.

posterior to the anterior-most point of the idiosoma. Collected mites of both species were singly weighed to obtain the initial mass using a Cahn microbalance (readability, reproducibility and linearity of $1.0 \mu \mathrm{g}$; Orion Cahn C-34, Thermo Electron Co., Beverly, MA, USA).

We used a high-speed CCD camera (Motion HG-100k, MotionXtra, Redlake, Tucson, AZ, USA) at 1000 frames s $^{-1}$ to film freshly collected mites of both species in the laboratory. Mites were housed in a white enameled dish warmed to surface temperatures of $21.5-55.5^{\circ} \mathrm{C}$ generated by a $200 \mathrm{~W}$ HMI discharge lamp or using heating tape, and substrate temperatures measured using a copperconstantan thermocouple attached to the surface using opaque white tape. The metal junction of the probe tip was left exposed and just free of the dish surface, providing a measure of temperature in the $1 \mathrm{~mm}$ air space occupied by the mites. The camera was focused immediately adjacent to the thermocouple to ensure accurate temperature estimates during filming. Stride frequency was calculated as the inverse of the stride period, which was determined from the high-speed video image analysis software (ImageJ, NIH, Bethesda, MD, USA). A minimum of five stride cycles was used to calculate each individual's mean stride frequency.

Mean running speeds were calculated for each recorded running sequence using LoggerPro Version 3 software (Vernier Systems, Beaverton, OR, USA) by manually digitizing the most anterior point of the idiosoma in each frame to track body movement and numerically differentiating the position data recorded at each point per frame. In this calculation a weighted mean of the slope of two points around each position was used to determine an mean velocity per frame. Different methods of analysis, including determining the mean velocity for each frame by subtracting subsequent positions and by taking a Savitsky-Golay derivative, which fits a polynomial to the three points around each position, produced results similar to the ones shown in this paper and the differences in calculated speeds between methods were smaller than the range of velocities measured for a typical data set. Mean running speeds were measured from recordings lasting $25-100 \mathrm{~ms}$, such that 25-100 velocities (1 measurement per frame) were used to determine the mean running speed of each individual at a given temperature. Because substrate temperatures were measured separately for each recording, $Q_{10}$ values for stride frequency and relative speed were calculated from linear regressions of the values over the specific temperature range.

Froude numbers $(F r)$, a commonly used dimensionless measure of speed normalized for body size, were calculated for both species:

$$
F r=\frac{v^{2}}{\boldsymbol{g} L},
$$

where $v=$ velocity of the mite, $\boldsymbol{g}=$ acceleration due to gravity, and $L=$ leg length. 


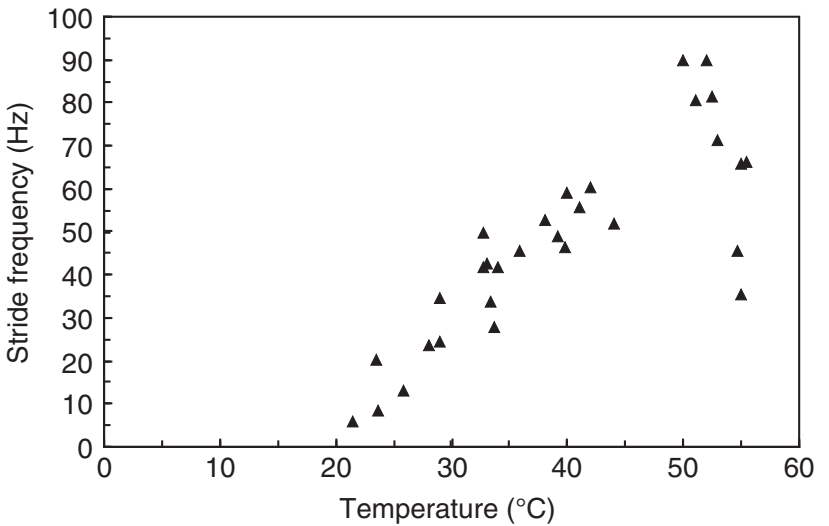

Fig. 2. Stride frequency $(\mathrm{Hz})$ of species 1 at varying experimental temperatures. Here and elsewhere (Figs 3, 4 and 6), individual data points are mean values determined from a single video sequence. Frequency increases approximately linearly as a function of ambient temperature until $50^{\circ} \mathrm{C}$ above which it declines steeply. The maximum frequency recorded was ca. $90 \mathrm{~Hz}$. Animals became inactive above $56^{\circ} \mathrm{C}$ and below $20^{\circ} \mathrm{C}(\mathrm{N}=5$ animals).

Leg lengths for each species were taken as the mean of all four leg pairs measured from a whole-mount specimen approximating the mean body length of animals used for the kinematic analyses.

\section{RESULTS}

Species 1 had a body mass of $182 \pm 70 \mu \mathrm{g}$ (mean \pm s.d.; $N=50$ animals) and species 2 had a body mass of $30.2 \pm 4.0 \mu \mathrm{g}(N=10$ animals $)$. Mean leg lengths for single representative specimens were $1.38 \pm 0.39 \mathrm{~mm}$ for species 1 and $0.84 \pm 0.14 \mathrm{~mm}$ for species 2 .

For species 1, measurements of absolute and relative running speeds and stride frequency were made over a temperature range from $21.5^{\circ} \mathrm{C}$ to $55.4^{\circ} \mathrm{C}$. Stride frequencies showed very little variation within a given trial, while running speed varied considerably as animals turned or encountered substrate irregularities. The mites were able to rotate over $100 \mathrm{deg}$ in a single stride cycle and then run abruptly in a new direction, attaining a steady speed and stride frequency within the succeeding stride. The maximum speed, averaged over at least 25 frames, was obtained for each recording. Stride frequency (Fig. 2), absolute running speed (Fig.3) and relative running speed (Fig.4) conform to standard physiological performance curves, increasing to maxima at approximately $50^{\circ} \mathrm{C}$ and decreasing sharply between $50^{\circ} \mathrm{C}$ and $55^{\circ} \mathrm{C}$. Both stride frequency and relative speed attain exceptionally high values: stride frequencies peak at approximately $90 \mathrm{~Hz}$ at $50-52^{\circ} \mathrm{C}$, and the maximum recorded relative speed is $133 \mathrm{BL} \mathrm{s}^{-1}$ at $42^{\circ} \mathrm{C}$ (Table 1). This species has a minimum locomotory temperature of approximately $20^{\circ} \mathrm{C}$, based both on observation and the running speed and stride frequency relationships. $Q_{10}$ values are similar for both relative speed and stride frequency between $30^{\circ} \mathrm{C}$ and $50^{\circ} \mathrm{C}$ (Table 2). Between $20^{\circ} \mathrm{C}$ and $30^{\circ} \mathrm{C}, Q_{10}$ values increase markedly, reflecting the sharp decline in running speed and, especially, stride frequency as the temperature approaches $20^{\circ} \mathrm{C}$.

Mean absolute running speeds of species 2 were lower than those measured for species 1 , although the relative speeds are comparable (Table 3). The highest relative speed recorded at $45^{\circ} \mathrm{C}$ was $129 B L \mathrm{~s}^{-1}$. Stride frequencies were higher than in species 1 , with mean values of $93 \mathrm{~Hz}$ and $112 \mathrm{~Hz}$ at $25^{\circ} \mathrm{C}$ and $45^{\circ} \mathrm{C}$, respectively.

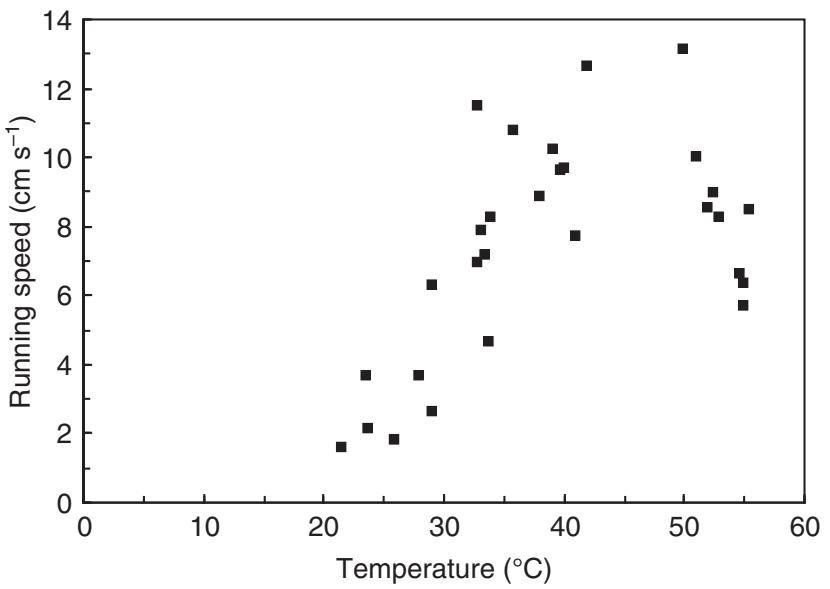

Fig. 3. Absolute running speed $\left(\mathrm{cm} \mathrm{s}^{-1}\right)$ for species 1 in temperatures ranging from $21.5^{\circ} \mathrm{C}$ to $55.4^{\circ} \mathrm{C}$. Like stride frequency, running speed increases approximately linearly with temperature up to $50^{\circ} \mathrm{C}$ and then declines sharply. The fastest absolute running speed recorded was $13.1 \mathrm{~cm} \mathrm{~s}^{-1}$ at $50^{\circ} \mathrm{C}(N=5$ animals $)$.

Frame-by-frame analyses of individual video recordings clearly show that both species of mites employ an alternating gait pattern, with the adjacent and contra-lateral limbs moving $180 \mathrm{deg}$ out of phase (Fig. 5). Stride lengths for species 1 were calculated by dividing running speed by stride frequency for values recorded at all temperatures (Fig. 6). Stride length showed no statistically measurable increase with increasing running speed $(P=0.76, N=27$ recordings from 5 animals; regression $t$-test). Mean stride length $(L)$ was $1.67 \pm 0.086 \mathrm{~mm}$ or approximately $60 \%$ of the theoretical maximum value of $2 L$.

Froude numbers were calculated from the compiled running speeds at different temperatures (Tables 1,3). Froude numbers (mean \pm s.e.m. $)$ for species 1 were $0.088 \pm 0.036\left(20-30^{\circ} \mathrm{C}\right), 0.58 \pm 0.073$ $\left(30-40^{\circ} \mathrm{C}\right)$ and $0.72 \pm 0.19\left(40-50^{\circ} \mathrm{C}\right)$. Corresponding values for species 2 were $0.090\left(25^{\circ} \mathrm{C}\right), 0.29\left(35^{\circ} \mathrm{C}\right)$ and $0.57 \pm 0.06\left(45^{\circ} \mathrm{C}\right)$.

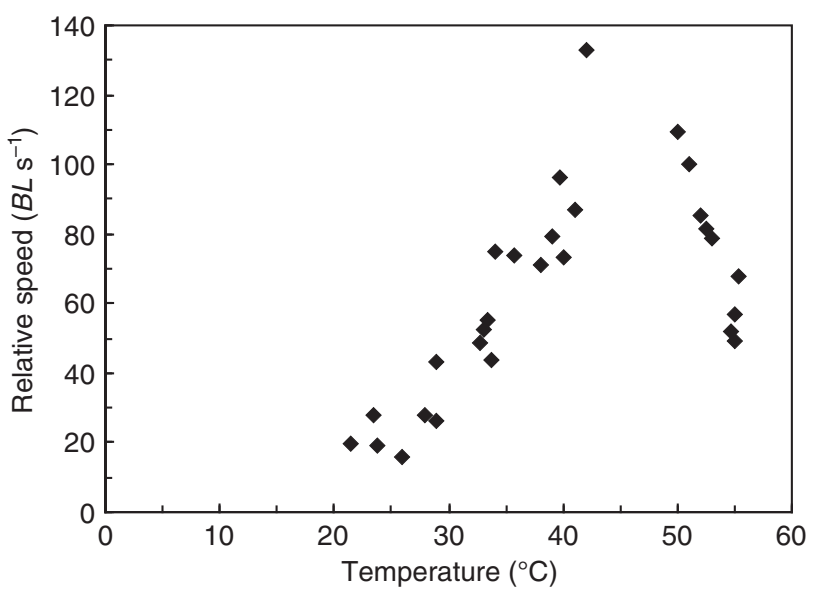

Fig. 4. Relative speed [body lengths $(B L) \mathrm{s}^{-1}$ ] for species 1 as a function of ambient temperature. The relationship to ambient temperature is similar to that seen for stride frequency and absolute running speed. The highest relative speed recorded was $133 \mathrm{BL} \mathrm{s}^{-1}$ at $42^{\circ} \mathrm{C}(N=5$ animals). 
Table 1. Absolute and relative running speeds and stride frequencies for species 1 at different substrate temperatures

\begin{tabular}{lccc}
\hline Temperature $\left({ }^{\circ} \mathrm{C}\right)$ & Absolute speed $\left(\mathrm{cm} \mathrm{s}^{-1}\right)$ & Relative speed $\left(B L \mathrm{~s}^{-1}\right)$ & Stride frequency $(\mathrm{Hz})$ \\
\hline $20-30$ & $3.1 \pm 0.62(7)$ & $25.8 \pm 3.4(7)$ & $18.6 \pm 3.8(7)$ \\
$30-40$ & $8.7 \pm 0.59(11)$ & $66.9 \pm 4.9(11)$ & $44.6 \pm 2.6(11)$ \\
$40-50$ & $10.6 \pm 0.91(6)$ & $100.6 \pm 9.3(5)$ & $66.2 \pm 6.2(6)$ \\
\hline
\end{tabular}

Values show means \pm s.e.m. $(N)$. BL, body length.

Table 2. $Q_{10}$ values for stride frequency and running speed for species 1

\begin{tabular}{lcc}
\hline Temperature range $\left({ }^{\circ} \mathrm{C}\right)$ & Stride frequency $(\mathrm{Hz})$ & Running speed $\left(\mathrm{cm} \mathrm{s}^{-1}\right)$ \\
\hline $20-30$ & $13.4 \pm 3.9(7)$ & $3.60 \pm 2.2(7)$ \\
$30-40$ & $1.51 \pm 0.51(11)$ & $1.45 \pm 0.74(11)$ \\
$40-50$ & $1.59 \pm 0.36(6)$ & $1.61 \pm 2.2(5)$ \\
\hline
\end{tabular}

Values show means \pm s.e.m. $(M) . Q_{10}$, temperature coefficient over a $10^{\circ} \mathrm{C}$ temperature range.

Stride frequencies for both species broadly correspond to values predicted from the interspecific scaling determined for animals over 10 orders of body mass (Fig. 7), whether using a least-squares regression for published data $\left(f=12.0 M_{\mathrm{b}}^{-0.148}\right)$ or using the same intercept and assuming an exponent of -0.17 . Although the values from mites include several experimental temperatures, the mean frequency recorded for species 1 over $30-40^{\circ} \mathrm{C}$ falls almost exactly on the extrapolated regression line for other running animals, which is derived largely from mammals using muscles operating over the same temperature range. Frequencies for species 2 exceed predicted values in all three temperature ranges (Fig. 7; Table 3).

\section{DISCUSSION}

Relative speeds for these mites are exceptionally high and comparable with values reported for the American cockroach Periplaneta americana $\left(40-50 B L \mathrm{~s}^{-1}\right.$ at $\left.23-26^{\circ} \mathrm{C}\right)$ (McConnell and Richards, 1955; Full and Tu, 1991). The highest observed values of $133 B L \mathrm{~s}^{-1}$ for species 1 at $42^{\circ} \mathrm{C}$ and $129 B L s^{-1}$ for species 2 at $45^{\circ} \mathrm{C}$ are apparently exceeded only by Cicindela eburneola, an Australian tiger beetle, with a maximum reported relative speed of $170 \mathrm{BL} \mathrm{s} \mathrm{s}^{-1}$ at an unspecified field temperature (Kamoun and Hogenhout, 1996). Relative speed scales non-linearly with body mass, at least for mammals, decreasing faster for body masses exceeding $30 \mathrm{~kg}$ (Iriarte-Diaz, 2002). A linear regression for mammals below $30 \mathrm{~kg}$ yields the scaling equation $v_{\mathrm{r}}=24.21 \mathrm{M}_{\mathrm{b}}{ }^{-0.09}$. Applying this to mite species 1 and 2 yields estimated values for $v_{\mathrm{r}}$ of $97.9 \mathrm{BL} \mathrm{s}{ }^{-1}$ and $115 \mathrm{BL} \mathrm{s} \mathrm{s}^{-1}$, respectively, which are similar to the values reported here at mammalian body temperatures (Fig.7). The highest absolute running speeds documented for invertebrates are those of another Australian tiger beetle Cicindela hudsoni $\left(2.5 \mathrm{~m} \mathrm{~s}^{-1}\right.$, at an unspecified field temperature) (Kamoun and Hogenhout, 1996) and the American cockroach $\left(1.5 \mathrm{~m} \mathrm{~s}^{-1}\right.$ at $\left.23-26^{\circ} \mathrm{C}\right)$ (Full and Tu, 1991).

Stride frequencies for Parateneriffia spp. exceed those currently documented for other arthropods. The stride frequency of $P$. americana, one of the fastest running invertebrates studied, ranges from $15 \mathrm{~Hz}$ to $27 \mathrm{~Hz}$ at $23-26^{\circ} \mathrm{C}$ (Full and $\mathrm{Tu}, 1991$ ), similar to values measured for species 1 over the same temperature range but only $18-30 \%$ of the values reported for species 2 . Stride frequencies are not available for the tiger beetles but are unlikely to exceed cockroach values more than 1.7-fold (the ratio of absolute running speeds) given their comparable size and leg length. In spite of their exceptional stride frequencies, however, Parateneriffia spp. show Froude numbers that fall well within the typical range for walking and running gaits at similar temperatures and indicate overall dynamic similarity to other terrestrial animals (Biewener, 2003). A Froude number is defined by the ratio of inertial to gravitational forces acting on a moving object. Among other things, similar Froude numbers support a direct relationship between mechanical power output and the product of body weight and forward speed, indicating that the primary forces acting on mites during locomotion are similar to those acting on much larger animals (Full, 1989).

The trade-off between muscle force generation $\left(F_{\mathrm{m}}\right)$ and contraction frequency is well described for non-weight-bearing muscle. The sound-producing muscles of toadfish and rattlesnakes show that the kinetics of calcium uptake and clearance, and successive steps in the contraction-relaxation cycle can be enhanced through selection to support ultra-high frequencies. This is accomplished, at least in part, by reducing the number of myofibrils to accommodate an enlarged SR and operating with fewer attached cross-bridges to allow for fast relaxation, both of which result in low force (Appelt et al., 1991; Rome, 2006). The present study shows that weight-bearing locomotory muscles can attain operating frequencies exceeding $80 \mathrm{~Hz}$ at $50^{\circ} \mathrm{C}$ (species 1) and exceeding $100 \mathrm{~Hz}$ at $45^{\circ} \mathrm{C}$ (species 2). The stride frequencies for Parateneriffia spp. measured between $30^{\circ} \mathrm{C}$ and $40^{\circ} \mathrm{C}$ are very close to those predicted from allometric scaling (Fig. 7) (Heglund et al., 1974; Full, 1989), indicating that kinetics of the activation-relaxation cycle are not constraining the muscle cycle frequencies. Were cross-bridge formation, calcium influx, calcium clearance or other components of the activation-relaxation cycle rate limiting, we would observe frequencies lower than those predicted by allometric scaling. Instead, conformity to the allometric scaling suggests that frequencies are probably determined by similar factors operating in other running animals. Representative Froude numbers also support this assertion. Frame-by-frame video analysis clearly shows that both species are able to adjust stride length and position between successive stride cycles, for example when adjusting to uneven terrain or turning abruptly. This observation indicates that the leg muscles are probably synchronous and under the control of discrete action potentials.

Table 3. Absolute and relative running speeds and stride frequencies for species 2 at different substrate temperatures

\begin{tabular}{lccr}
\hline Temperature $\left({ }^{\circ} \mathrm{C}\right)$ & Absolute speed $\left(\mathrm{cm} \mathrm{s}^{-1}\right)$ & Relative speed $\left(B L \mathrm{~s}^{-1}\right)$ & Stride frequency $(\mathrm{Hz})$ \\
\hline 25 & $2.72(2)$ & $45.3(2)$ & $93.1(2)$ \\
35 & $4.87(2)$ & $81.2(2)$ & $95.5(2)$ \\
45 & $6.87 \pm 0.65(4)$ & $114.5(4)$ & $112.4 \pm 5.4(4)$ \\
\hline
\end{tabular}

Values show means \pm s.e.m. $(M)$. BL, body length. 

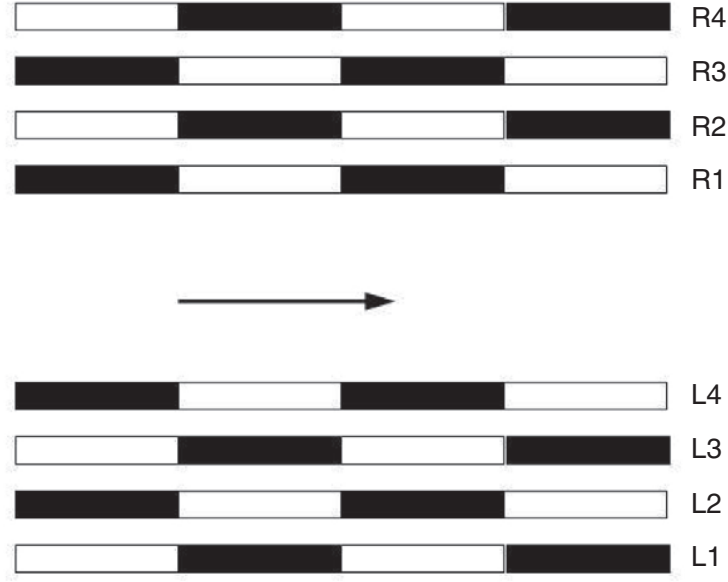

Fig. 5. Diagrammatic footfall pattern for species 1. The mites adopt an alternating gait pattern. Black bars represent legs in stance phase (contacting the ground), while open bars represent lifted legs. The arrow shows the direction of walking. The stance phase corresponds to the duration of limb flexion and occupies approximately $50 \%$ of each limb cycle. At any given time, the legs making contact will be R1, L2, R3, L4 or L1, R2, L3, R4.

One stride period for species 2 during running lasted 8-10.5 ms. Video analysis of both species shows a duty cycle of approximately 0.5 (stance phase:cycle period; Fig. 5). Assuming leg protractors and retractors relax completely by the end of the corresponding limb stroke, each muscle contraction cycle could last no more than 4-5ms, and may be considerably shorter. Thus, the three major kinetic steps in muscle activation $-\mathrm{Ca}^{2+}$ influx from the $\mathrm{SR}, \mathrm{Ca}^{2+}$ binding to troponin $\mathrm{C}$ and actin-myosin cross-bridge formation to generate force and reach peak tension - must be completed well within this period, probably within 2-3 ms. In the remaining 2-3 ms, SR $\mathrm{Ca}^{2+}$ ATPases and parvalbumin must re-sequester $\mathrm{Ca}^{2+}$ and $\mathrm{Ca}^{2+}$ must be released from the regulatory domain to induce cross-bridge detachment, allowing the force to decrease to zero (Rome and Lindstedt, 1998; Rome, 2006). Based on evidence from the basal chelicerate Limulus, it is probable that arachnids, like vertebrates, utilize troponin $\mathrm{C}$ and tropomyosin movement in thin-filament-based regulation of contraction (Lehman and Szent-Gyorgyi, 1975; Lehman et al., 1998). While the muscle physiology of these mite muscles awaits study, the operating stride frequencies during running require that the kinetic components of muscle activation and relaxation be exceptional. In particular, the calcium transient must have a half-width significantly shorter than vertebrate fasttwitch fibers (Baylor and Hollingworth, 1988; Baylor and Hollingworth, 2003) and probably similar to values seen in toadfish sonic muscle $\left(1.5 \mathrm{~ms}\right.$ at $\left.25^{\circ} \mathrm{C}\right)$ (Rome et al., 1996).

The broader question remains of how these mites attain such remarkable operating frequencies in weight-bearing locomotory muscles given the force-velocity trade-off. Relative muscle force $\left(F_{\mathrm{m}} / M_{\mathrm{b}}\right)$ is predicted to scale as $M_{\mathrm{b}}{ }^{-0.33}$ (Schmidt-Nielsen, 1984), so the muscles of smaller animals can generate requisite forces for locomotion with a reduced myofibril volume. This allows them to invest a larger volume of SR to facilitate rapid calcium cycling. Several factors may also enhance force generation while utilizing a reduced myofibril volume. The mites utilize only one gait and show only small variation in running speed at a given temperature, indicating that the major leg protractors and retractors may comprise a single fast-twitch fiber type. The fibers may also operate over a small range of lengths to exploit the peak of the length-tension curve.

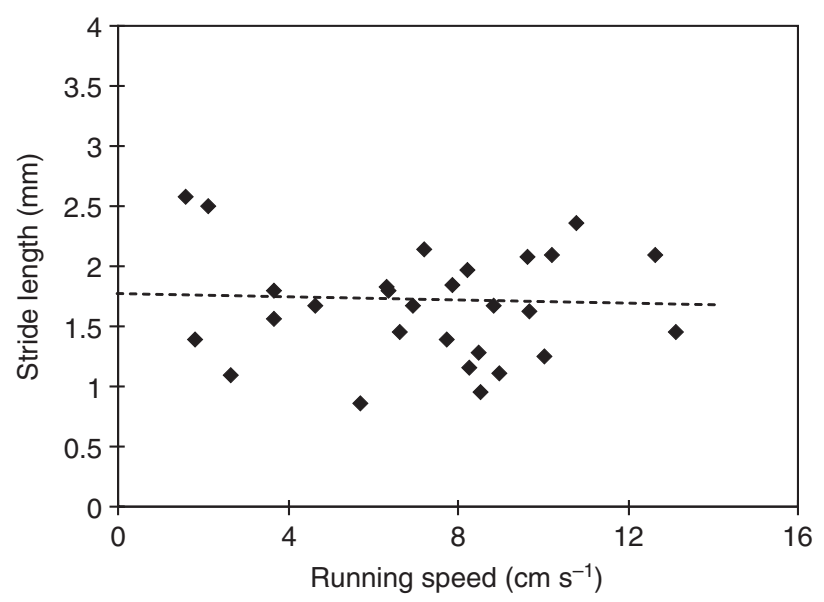

Fig. 6. Variation in stride length $(L, \mathrm{~mm})$ as a function of running speed $\left(\mathrm{cm} \mathrm{s}^{-1}\right)$ for species 1. The least-squares regression line is shown. Stride length shows no significant change over different running speeds ( $N=5$ animals).

Both species run intermittently, both in the field and in the lab, seldom traveling for more than $4-5 \mathrm{~s}$ in one burst, indicating that the locomotory fibers may be anaerobic. This would allow them to trade mitochondrial volume for greater myofibril volume. Small size and the efficiency of tracheal gas exchange would facilitate rapid removal of anaerobic end products. Furthermore, arachnids may utilize their limb's elastic sclerites for the storage and release of elastic energy when flexing and extending their leg joints during running (Sensenig and Schultz, 2003), and this could confer some energy saving, particularly in locomotion over uneven terrain (Dudek and Full, 2006).

Mites, like spiders and some other arachnids, lack extensor muscles and may extend their legs hydraulically. Hydraulic limb extension is thought to be the ancestral trait, perhaps with a supplementary role of cuticular elastic energy storage (Parry and Brown, 1959a; Parry and Brown, 1959b; Shultz, 1989; Sensenig and Shultz, 2003).

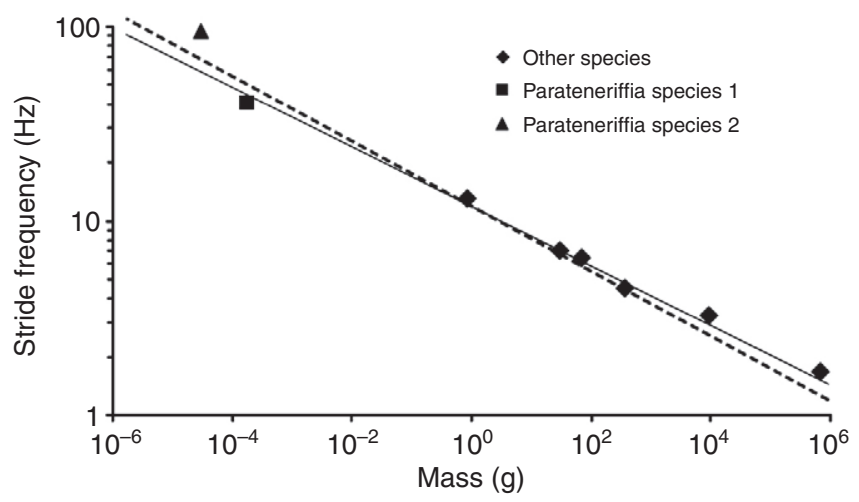

Fig. 7. Scaling of stride frequency during running with body mass. Diamonds represent published data for horse, dog, rat and mouse (Heglund et al., 1974), crab (Blickhan and Full, 1987) and cockroach (Full and Tu, 1991). Mean frequencies for both species of Parateneriffia averaged for the temperature range of $30-40^{\circ} \mathrm{C}$ are shown with square and triangular symbols. The least-squares regression for the published data (solid line) is $12.0 \mathrm{M}_{\mathrm{b}}^{-0.148}$. The broken line shows the predicted scaling, assuming an exponent of -0.17 (see text) and the same constant. Extrapolated curves provide a reasonable estimate of the mite stride frequencies, with species 1 falling almost exactly on the regression line for the published data, and species 2 falling above both curves. 
Movement of hemolymph in and out of flexing and extending limbs will depend on the hemolymph viscosity. If this represents a ratelimiting factor for Parateneriffia, the $Q_{10}$ for stride frequency should correspond closely to the $Q_{10}$ for fluidity of dilute aqueous solutions over the same temperature range (ca. 1.2) (Sengers and Watson, 1986). Our higher $Q_{10}$ values for species 1 may argue against this. Moreover, the importance of leg extension in generating propulsive force probably differs among the leg pairs in spite of the fact that all pairs operate at the same stepping frequency. In both species, the first three pairs primarily employ protraction and retraction in the stepping cycle, while the fourth pair primarily utilizes extension and flexion, i.e. the leading legs move the body by pulling it forward, while the hind legs work to push the body. Both $Q_{10}$ values and limb movements therefore indicate that hemolymph viscosity and hydraulic limb extension are not significant rate-limiting parameters. This is, again, consistent with the close congruence between observed frequencies and predicted values from interspecific scaling. Given the very high viscous drag predicted from Pouiseuille's law for hydraulic fluid flow in very small limbs (Sensenig and Shultz, 2003), elastic sclerites probably provide the primary means of leg extension in these mites.

The increase in running speed as a function of temperature in Parateneriffia species 1 is accomplished by increasing stride frequency but without any significant change in stride length (Fig. 6). The similar $Q_{10}$ values for stride frequency and running speed for species 1 are consistent with an unvarying stride length (Table2). In this respect, species 1 differs from the cockroach P. americana (Full and Tu, 1991) and vertebrates (Biewener, 2003), both of which generate faster running speeds primarily by increasing stride length rather than frequency. Given that the mites assume one gait at all speeds, and do not transition to a gait with an aerial phase, stride length is necessarily constrained by limb spacing. Most vertebrates avoid this constraint by employing gait transitions with an increasing aerial phase, and cockroaches increase stride length by transitioning to quadrupedal and bipedal running at maximum speeds (Full and Tu, 1991).

It is unclear whether relative speed reaches a maximum value with decreasing size. Although smaller animals generate larger relative muscle forces for a given myofibril volume, they are at the same time constrained by larger relative drag forces. There are currently insufficient data for species below $1 \mathrm{~g}$ in mass to allow an assessment of how these two opposing factors influence the scaling between mass and relative speed. Despite the good prediction of the relative speeds of these mite species using allometric equations derived from mammals (Iriarte-Diaz, 2002), similar relative speeds are also attained by cockroaches and tiger beetles, which exceed the mites in mass by 3-4 orders of magnitude. This indicates that different scaling laws may apply, with drag forces perhaps imposing ultimate constraints on relative speed in small running arthropods.

LIST OF SYMBOLS AND ABBREVIATIONS
body length
stride frequency
muscle force
Froude number
gravitational acceleration
leg length
body mass
sarcoplasmic reticulum
running velocity
relative speed

\section{ACKNOWLEDGEMENTS}

We thank David Tanenbaum for technical assistance with SEM for mite identification, Thomas Vasquez for use of the Cahn microbalance, Ivo Ros for helpful discussions on kinematics, and the valuable feedback of anonymous reviewers. Purchase of the Motion HG-100k camera was made possible by NSF grant MRI 0722532 . The research was supported in part by a Rose Hills Foundation Summer Fellowship to G.C.W.

\section{REFERENCES}

Appelt, D., Shen, V. and Franzini-Armstrong, C. (1991). Quantitation of Ca ATPase, feet and mitochondria in superfast muscle fibres from the toadfish Opsanus tau. J. Muscle Res. Cell Motil. 12, 543-552.

Baylor, S. M. and Hollingworth, S. (1988). Fura-2 calcium transients in frog skeletal muscle fibres. J. Physiol. 403, 151-192.

Baylor, S. M. and Hollingworth, S. (2003). Sarcoplasmic reticulum calcium release compared in slow-twitch and fast-twitch fibres of mouse muscle. J. Physiol. 551, 125138.

Biewener, A. A. (2003). Animal Locomotion. New York, NY: Oxford University Press. Blickhan, R. and Full, R. J. (1987). Locomotion energetics of the ghost crab: II. Mechanics of the center of mass during walking and running. J. Exp. Biol. 130, 155174.

Byrne, D. N., Buchmann, S. L. and Spangler, H. G. (1998). Relationship between wing loading, wingbeat frequency and body mass in homopterous insects. J. Exp. Biol. 135, 9-23.

Dudek, D. M. and Full, R. J. (2006). Passive mechanical responses of legs from running insects. J. Exp. Biol. 209, 1502-1515.

Full, R. J. (1989). Mechanics and energetics of terrestrial locomotion: bipeds to polypeds. In Energy Transformations in Cells and Organisms (ed. W. Wieser and E. Gnaiger), pp. 175-182. Stuttgart: Georg Thieme.

Full, R. J. and Tu, M. S. (1991). Mechanics of a rapid running insect: two-, four-, and six-legged locomotion. J. Exp. Biol. 156, 215-231.

Heglund, N. C., Taylor, C. R. and McMahon, T. A. (1974). Scaling stride frequency and gait to animal size: mice to horses. Science 186, 1112-1113.

Iriarte-Diaz, J. (2002). Differential scaling of locomotor performance and large terrestrial mammals. J. Exp. Biol. 205, 2897-2908.

Jones, J. H. and Lindstedt, S. L. (1993). Limits to maximal performance. Annu. Rev. Physiol. 55, 547-569.

Josephson, R. K. and Young, D. (1985). A synchronous insect muscle with an operating frequency greater than $500 \mathrm{~Hz}$. J. Exp. Biol. 118, 185-208.

Judson, M. (1994). Studies on the morphology and systematics of the Teneriffiidae (Acari, Prostigmata) 1, A new species of the Neoteneriffiola from Namibia. Acarologica 35, 115-131.

Kamoun, S. and Hogenhout, S. A. (1996). Flightlessness and rapid terrestrial locomotion in tiger beetles of the Cicindela L. subgenus Rivacindela van Nidek from saline habitats of Australia (Coleoptera: Cicindelidae). Coleopt. Bull. 50, 221-230.

Krantz, G. W. (1978). A Manual of Acarology. Corvallis, OR: Oregon State University Book Stores.

Lehman, W. and Szent-Gyorgyi, A. G. (1975). Regulation of muscular contraction. Distribution of actin control and myosin control in the animal kingdom. J. Gen. Physiol. 66, 1-30.

Lehman, W., Craig, R. and Vibert, P. (1998). $\mathrm{Ca}^{2+}$-induced tropomyosin movement in Limulus thin filaments revealed by three-dimensional reconstruction. Nature 368, 65-67.

Luxton, M. (1993). The genus Heteroteneriffia Hirst (Acari: Prostigmata: Teneriffiidae) Zool. Anz. 230, 103-109.

McConnell, E. and Richards, A. G. (1955). How fast can a cockroach run? Bull. Brooklyn Entomol. Soc. 50, 36-43.

McDaniel, B., Morihara, D. and Lewis, J. K. (1976). The family Teneriffiidae Thor, with a new species from Mexico. Ann. Entomol. Soc. Am. 69, 527-537.

Parry, D. A. and Brown, R. H. J. (1959a). The hydraulic mechanism of the spider leg. J. Exp. Biol. 36, 423-433.

Parry, D. A. and Brown, R. H. J. (1959b). The jumping mechanism of salticid spiders. J. Exp. Biol. 36, 654-666.

Pennycuick, C. J. (1975). On the running of the gnu (Connochaetes taurinus) and other animals. J. Exp. Biol. 63, 775-799.

Pringle, J. W. S. (1949). The excitation and contraction of the flight muscles of insects. J. Physiol. 108, 226-232.

Rome, L. C. (2006). Design and function of superfast muscles: new insights into the physiology of skeletal muscle. Ann. Rev. Physiol. 68, 193-221.

Rome, L. C. and Lindstedt, S. L. (1998). The quest for speed: muscles built for highfrequency contractions. News Physiol. Sci. 13, 261-268.

Rome, L. C., Syme, D. A., Hollingworth, S., Lindstedt, S. L. and Baylor, S. M. (1996). The whistle and the rattle: the design of sound producing muscles. Proc. Nat. Acad. Sci. USA 93, 8095-8100.

Schaeffer, P. J., Conley, K. E. and Lindstedt, S. L. (1996). Structural correlates of speed and endurance in skeletal muscle: the rattlesnake tailshaker muscle. J. Exp. Biol. 198, 351-358.

Schmidt-Nielsen, K. (1984). Scaling. Why is Animal Size so Important? Cambridge: Cambridge University Press.

Sengers, J. V. and Watson, J. T. R. (1986). Improved international formulations for the viscosity and thermal conductivity of water substance. J. Phys. Chem. Ref. Data 15, 1291-1314.

Sensenig, A. T. and Shultz, J. W. (2003). Mechanics of cuticular elastic energy storage in leg joints lacking extensor muscles in arachnids. J. Exp. Biol. 206, 771-784.

Shultz, J. W. (1989). Morphology of locomotor appendages in Arachnida: evolutionary trends and phylogenetic implications. Zool. J. Linn. Soc. 97, 1-56.

Sotavalta, O. (1947). The flight-tone (wing-stroke frequency) of insects. Acta Entomol. Fenn. 4, 1-117.

Sotavalta, O. (1952). Flight-tone and wing-stroke frequency of insects and the dynamics of insect flight. Nature 170, 1057-1058.

Syme, D. A. and Josephson, R. K. (2002). How to build fast muscles: synchronous and asynchronous designs. Integr. Comp. Biol. 42, 762-770. 